University of Nebraska - Lincoln

DigitalCommons@University of Nebraska - Lincoln

\title{
Retrieval of subpixel snow covered area, grain size, and albedo from MODIS
}

Thomas H. Painter

University of Utah

Karl Rittger

University of California - Santa Barbara

Ceretha McKenzie

US Army Cold Regions Research and Engineering Laboratory

Peter Slaughter

University of California - Santa Barbara

Robert E. Davis

US Army Cold Regions Research and Engineering Laboratory

See next page for additional authors

Follow this and additional works at: https://digitalcommons.unl.edu/usarmyresearch

Part of the Operations Research, Systems Engineering and Industrial Engineering Commons

Painter, Thomas H.; Rittger, Karl; McKenzie, Ceretha; Slaughter, Peter; Davis, Robert E.; and Dozier, Jeff, "Retrieval of subpixel snow covered area, grain size, and albedo from MODIS" (2009). US Army Research. 83.

https://digitalcommons.unl.edu/usarmyresearch/83

This Article is brought to you for free and open access by the U.S. Department of Defense at DigitalCommons@University of Nebraska - Lincoln. It has been accepted for inclusion in US Army Research by an authorized administrator of DigitalCommons@University of Nebraska - Lincoln. 


\section{Authors}

Thomas H. Painter, Karl Rittger, Ceretha McKenzie, Peter Slaughter, Robert E. Davis, and Jeff Dozier 


\title{
Retrieval of subpixel snow covered area, grain size, and albedo from MODIS
}

\author{
Thomas H. Painter ${ }^{\mathrm{a}, *}$, Karl Rittger ${ }^{\mathrm{b}}$, Ceretha McKenzie ${ }^{c}$, Peter Slaughter ${ }^{\mathrm{b}}$, Robert E. Davis ${ }^{c}$, Jeff Dozier ${ }^{\mathrm{b}}$ \\ a Department of Geography, University of Utah, Salt Lake City, UT 84112, USA \\ ${ }^{\mathrm{b}}$ Donald Bren School of Environmental Science and Management, University of California, Santa Barbara, CA 93106, USA \\ c US Army Cold Regions Research and Engineering Laboratory, Hanover, NH 03755, USA
}

\section{A R T I C L E I N F O}

\section{Article history:}

Received 10 July 2008

Received in revised form 30 December 2008

Accepted 1 January 2009

\section{Keywords:}

Snow

Grain size

Albedo

Spectral mixture analysis

MODIS

\begin{abstract}
A B S T R A C T
We describe and validate a model that retrieves fractional snow-covered area and the grain size and albedo of that snow from surface reflectance data (product MOD09GA) acquired by NASA's Moderate Resolution Imaging Spectroradiometer (MODIS). The model analyzes the MODIS visible, near infrared, and shortwave infrared bands with multiple endmember spectral mixtures from a library of snow, vegetation, rock, and soil. We derive snow spectral endmembers of varying grain size from a radiative transfer model specific to a scene's illumination geometry; spectra for vegetation, rock, and soil were collected in the field and laboratory. We validate the model with fractional snow cover estimates from Landsat Thematic Mapper data, at $30 \mathrm{~m}$ resolution, for the Sierra Nevada, Rocky Mountains, high plains of Colorado, and Himalaya. Grain size measurements are validated with field measurements during the Cold Land Processes Experiment, and albedo retrievals are validated with in situ measurements in the San Juan Mountains of Colorado. The pixelweighted average RMS error for snow-covered area across 31 scenes is $5 \%$, ranging from $1 \%$ to $13 \%$. The mean absolute error for grain size was $51 \mu \mathrm{m}$ and the mean absolute error for albedo was $4.2 \%$. Fractional snow cover errors are relatively insensitive to solar zenith angle. Because MODSCAG is a physically based algorithm that accounts for the spatial and temporal variation in surface reflectances of snow and other surfaces, it is capable of global snow cover mapping in its more computationally efficient, operational mode.
\end{abstract}

(c) 2009 Elsevier Inc. All rights reserved.

\section{Introduction}

Snow cover and its melt dominate regional climate and hydrology in many of the world's mountainous regions. One-sixth of Earth's population depends on snow- or glacier-melt for water resources, and people in these areas generate one-fourth of the global domestic product (Barnett et al., 2005). Recent analyses of long-term surface observations show a declining snowpack in the lower elevations in the western U.S. (Barnett et al., 2008; Howat \& Tulaczyk, 2005; Mote et al., 2005), and investigations in the San Juan Mountains of Colorado show a positive feedback between dust from the Colorado Plateau and early snowmelt (Painter et al., 2007a). Dust deposited in the snowpack causes it to melt out three to five weeks earlier than it did before agricultural disturbance of the western U.S. in the second half of the 19th century, as revealed by lake sediment analysis (Neff et al., 2008).

Operationally, seasonal forecasts of snowmelt-generated streamflow are leveraged through empirical relations based on past snowmelt periods. These historical data show that climate is changing, but the changes reduce the reliability of the empirical relations (Milly

\footnotetext{
* Corresponding author.

E-mail addresses: painter@geog.utah.edu (T.H. Painter), krittger@bren.ucsb.edu (K. Rittger), ceretha1@mac.com (C. McKenzie), peter@bren.ucsb.edu (P. Slaughter), Robert.E.Davis@erdc.usace.army.mil (R.E. Davis), dozier@bren.ucsb.edu (J. Dozier).
}

et al., 2008). Therefore optimal future management of snowmeltderived water resources will require explicit physical models driven by remotely sensed data along with enhancement of the surface networks (Bales et al., 2006). The most critical snow properties for modeling the energy and mass balance of the snow cover are its spatial extent and albedo (Blöschl, 1991; Dozier \& Painter, 2004).

We describe and validate an automated model for the retrieval of subpixel snow-covered area and snow grain size that uses surface reflectance data from MODIS, NASA's Moderate Resolution Imaging Spectroradiometer. Based on an earlier model developed for an imaging spectrometer (Painter et al., 2003) and adapted to multispectral data, this new model (MODSCAG-MODIS Snow-Covered Area and Grain size) uses multiple endmember spectral mixture analysis (Roberts et al., 1998) to simultaneously solve for subpixel snowcovered area and grain size of the fractional snow cover. Grain size estimates coupled with an estimate of impurity concentration can then be used to estimate the snow's albedo. Grain size is the snow parameter that determines its spectral albedo throughout the nearinfrared and shortwave infrared wavelengths, while absorbing impurities and, for shallow snow only, snow water equivalent reduce the albedo in the visible spectrum (Warren, 1982). Here, we describe the MODSCAG model and assess its accuracy with Thematic Mapper data, field measurements of grain size, and in situ measurements of albedo. 


\section{Remote sensing of snow-covered area and grain size}

The widely used MODIS snow cover product, MOD10A1 (Hall et al., 2002, 2006), is a "binary" map, whereby each pixel is classified as either "snow" or "not snow." The algorithm's heritage traces back to retrieval of snow-covered area and qualitative grain size from the Landsat Thematic Mapper using normalized band differences (Dozier, 1984,1989 ) and the recognition that snow could be discriminated from clouds in the shortwave-infrared region (Crane \& Anderson, 1984). Version 005 of MOD10A1 contains a new fractional snow cover product developed from a linear fit of binary Thematic Mapper snow cover (averaged into $500 \mathrm{~m}$ bins for fractional snow cover of MODIS) to the normalized difference snow index of MODIS bands 2 and 5 for a collection of snow covered regions (Kaufman et al., 2002; Salomonson \& Appel, 2004, 2006). Vikhamar and Solberg (2003) mapped fractional snow cover in forests with MODIS using a land cover fraction map and linear mixture analysis.

From geostationary platforms, snow cover is generally mapped as binary. However, a fractional snow cover algorithm developed for mapping snow depth on the plains and level forested terrain uses the single visible band from current Geostationary Operational Environmental Satellite (GOES) platforms to infer a fractional snow cover (Romanov et al., 2003).

Tedesco and Kokhanovsky (2007) mapped grain size assuming $100 \%$ snow cover in the North Park of Colorado where surface measurements were made during the Cold Land Processes Experiment. Their grain size errors were $5 \%$ to $40 \%$. Grain size has also been mapped over Antarctica using a normalized difference approach between the MODIS band 1 (620-670 nm) and MODIS Band 2 (841876) radiances from pure snow pixels (Scambos et al., 2007). The precursor model to MODSCAG using imaging spectrometer data retrieved grain size and albedo with RMS errors of $50 \mu \mathrm{m}$ for grain size and 0.02 for albedo (Painter et al., 2003). The Version 004 MODIS release contained a snow albedo product (Klein \& Stroeve, 2002) that assumes that the mapped pixel has $100 \%$ snow cover; it was evaluated on the fairly level Greenland ice sheet (Stroeve et al., 2005) where the assumption that the snow cover is uniform across the pixel is likely correct. The RMS error between the MODIS retrievals and automated weather stations was $~ 7 \%$. Liang et al. (2005) evaluated a "direct retrieval algorithm" for snow albedo over Greenland with errors of $4 \%$.

Experiments with the Global Imager (GLI) on ADEOS-II show quantitative results for retrieval of snow grain size and impurity content (Aoki et al., 2007). The retrieval algorithms use absolute reflectance values in discrete channels (Stamnes et al., 2007), thereby requiring that the local solar illumination angle on the pixel is known, and they also apply only to pixels with $100 \%$ snow cover. Their algorithm has been tested over relatively level areas at four sites in Alaska and Hokkaido.

\section{Model description}

In contrast to those models relying on absolute reflectance, the MODSCAG model uses the relative shape of the snow's spectrum and can be applied to mountainous areas where the local solar illumination angle on a slope is often unknown because of co-registration errors between the image and a digital elevation model. The MODSCAG model estimates the fraction of each pixel that is covered by snow, along with the grain size of that snow. Their simultaneous solution is necessary because the spectral reflectance of snow is sensitive to grain size (Warren, 1982) and the spectrum of the mixed pixel is sensitive to the spectral reflectance of the snow fraction (Painter et al., 1998). Therefore, we allow the snow's spectral reflectance to vary pixel-by-pixel and thereby address the spatial heterogeneity that characterizes snow in rough terrain, and we estimate the albedo for the subpixel snow cover instead of the composite albedo of the pixel.

\subsection{Snow endmembers, etc.}

In spectral mixture analysis, an endmember is the spectral reflectance of a pure surface cover. MODSCAG uses libraries of snow endmembers generated with model calculations of snow reflectance for monodispersions of spheres of radii $10-1100 \mu \mathrm{m}$ by $10 \mu \mathrm{m}$ and solar zenith angles ranging from $0^{\circ}$ to $85^{\circ}$. We calculate their single-scattering properties over each MODIS band with Mie theory (Mie, 1908; Nussenzveig \& Wiscombe, 1980; Wiscombe, 1980) and the hemispherical-directional reflectance factor $R_{\lambda}$ (Schaepman-Strub et al., 2006) with a discrete-ordinates radiative transfer model (DISORT, Stamnes et al., 1988):

$R_{\lambda}\left(\theta_{0}, \phi_{0} ; \theta_{r}, \phi_{r}\right)=\frac{\pi L_{\lambda}\left(\theta_{r}, \phi_{r}\right)}{\cos \theta_{0} E_{\lambda, \text { dir }}\left(\theta_{0}, \phi_{0}\right)+E_{\lambda, \text { diff }}}$

where $\theta$ and $\phi$ are zenith and azimuth angles; the subscripts 0 and $r$ signify incidence and reflectance $L_{\lambda}$ is reflected radiance; $E_{\lambda \text {,dir }}$ is spectral direct beam irradiance; and $E_{\lambda, \text { diff }}$ is spectral diffuse irradiance. Table 1 shows the spectral bandpasses for the seven MODIS land reflectance bands. Generally, $R_{\lambda}\left(\theta_{0}, \phi_{0}, \theta_{r}, \phi_{r}\right)$ is a function of the relative difference between the azimuth angles $\left|\phi_{0}-\phi_{r}\right|$ rather than of their absolute values.

\subsection{Rock, soil, vegetation, and lake ice endmembers}

We use hyperspectral reflectance measurements for vegetation, rock, soil, and lake ice made in the field and laboratory with an Analytical Spectral Devices field spectroradiometer (http://www.asdi.com). We convolved these spectra from $1 \mathrm{~nm}$ spectral resolution to the MODIS bandpasses (Table 1) using the instrument spectral response functions. Fig. 1 shows a subset of the snow and non-snow spectral library.

\subsection{MODIS spectral surface reflectance}

The MODIS product suite includes MOD09GA, atmospherically corrected surface hemispherical-directional reflectance factor (available from the Land Processes Distributed Active Archive Center, http:// lpdaac.usgs.gov/). The algorithm uses the 6S radiative transfer code (Kotchenova et al., 2006; Kotchenova \& Vermote, 2007), which accounts for elevated targets, realistic mixed atmospheres, Lambertian and anisotropic ground surfaces, and gaseous absorption. Also included in the MOD09GA product is a cloud state variable, which has visually evident errors of both omission and commission in the snow-cloud discrimination (Hall \& Riggs, 2007). In the validation effort, in order to avoid errors related to misclassification of clouds as snow or vice versa, we created an ad hoc cloud mask by combining the MOD09GA product with our estimate of the particle size of the "cloud." Clouds with a too-large particle size are mapped as snow instead, and snow with a too-fine grain size is considered cloud. This collection of steps is specific to this study and does not yet represent a proposed snow/cloud discrimination algorithm.

At time of press, there has been no assessment of the spectral uncertainty of the MOD09GA product over snow cover (Vermote \& Kotchenova, in press; E. Vermote, personal communication). Therefore,

Table 1

Spectral interval and pixel resolution, at nadir, for the seven MODIS land reflectance bands [http://modis.gsfc.nasa.gov/about/specifications.php, accessed 05 July 2008]

\begin{tabular}{lll}
\hline Band & Bandwidth $(\mu \mathrm{m})$ & Spatial resolution $(\mathrm{m})$ \\
\hline 1 & $0.620-0.670$ & 250 \\
2 & $0.841-0.876$ & 250 \\
3 & $0.459-0.479$ & 500 \\
4 & $0.545-0.565$ & 500 \\
5 & $1.230-1.250$ & 500 \\
6 & $1.628-1.652$ & 500 \\
7 & $2.105-2.155$ & 500 \\
\hline
\end{tabular}



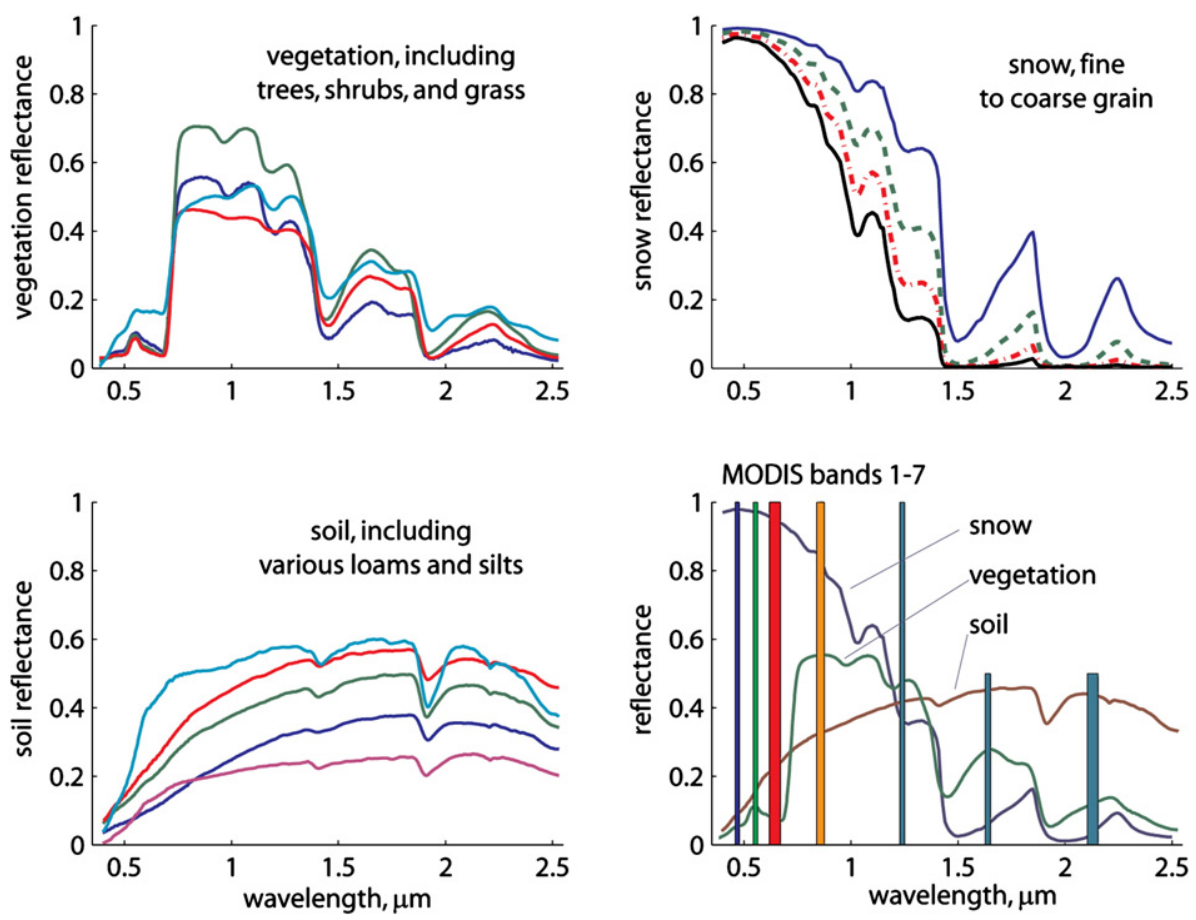

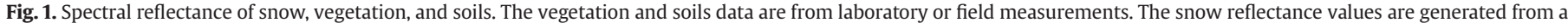
radiative transfer model. In the lower right graph, the MODIS land bands are shown, along with one sample spectrum each from vegetation, snow, and soil.

we do not assess the uncertainty of MODSCAG as related to what would be fictitious uncertainties. However, we are preparing an effort to assess these uncertainties over snow with the Surface Reflectance team.

\subsection{Spectral mixture analysis}

Linear spectral mixture analysis assumes that the radiance measured at the sensor is a linear combination of radiances reflected from individual surfaces. Sophisticated versions of the technique have been used to infer the fractional cover of vegetation cover (Okin, 2007; Roberts et al., 1998), soils and rock cover (Asner \& Heidebrecht, 2002; Ballantine et al., 2005), urban landscapes (Powell et al., 2007), and snow cover (Nolin et al., 1993; Painter et al., 2003; Rosenthal \& Dozier, 1996; Vikhamar \& Solberg, 2003). The linear assumption is appropriate for spatial scenarios such as snow and rock above timberline where the surface is near planar and interactions between different surface covers is minor at the subpixel scale. Nonlinear analysis, which accounts for multiple scattering between surfaces, is necessary when the surface has a structure, such as vegetation that reflects and transmits radiation to the snow or soil substrate and other vegetation (Roberts et al., 1993). However, nonlinear mixtures can be analyzed with linear models through the use of canopy-level endmembers (those that include the multiple scattering), which we use in the MODSCAG spectral libraries.

Spectral mixture analysis is based on a set of simultaneous linear equations that are solved for the components of the pixel-averaged MODIS surface reflectance, i.e. product MOD09GA:

$R_{S, \lambda}=\sum_{i=1}^{N} F_{i} R_{\lambda, i}+\varepsilon_{\lambda}$

where $F_{i}$ is the fraction of endmember $i ; R_{\lambda, i}$ is the hemisphericaldirectional reflectance factor, defined in Eq. (1), of endmember $i$ at wavelength $\lambda ; N$ is the number of spectral endmembers; and $\varepsilon_{\lambda}$ is the residual error at $\lambda$ for the fit of the $N$ endmembers. The least-squares fit to $F_{i}$ can be solved by several standard methods (Golub \& Van Loan, 1996). Here we use the Modified Gram-Schmidt orthogonalization.
Analysis of residuals reveals spectral regions of poor modeling and can be useful for separating near-degenerate spectra (Roberts et al., 1993).

The root mean squared error provides a spectrum-wide measure of fit for a mixture model:

$\operatorname{RMSE}=\left(\frac{1}{M} \sum_{\lambda=1}^{M} \varepsilon_{\lambda}^{2}\right)^{1 / 2}$

where $M$ is the number of bands used. RMSE is a fundamental metric for optimizing selection of model results in the multiple endmember spectral mixture analysis (Dennison \& Roberts, 2003).

The estimate of subpixel snow-covered area comes from the shade-normalized snow fraction $f_{\mathrm{SCA}}$ :

$f_{\mathrm{SCA}}=\frac{F_{S}}{\sum_{p \in S, v, r} F_{p}}=\frac{F_{S}}{1-F_{\text {shade }}}$

where $F_{S}$ is the initial snow spectral fraction from the least-squares solution to Eq. (2), $F_{p}$ are the physical spectral fractions (non-shade), and $F_{\text {shade }}$ is the spectral fraction of photometric shade. Normalizing by the additive complement of the shade fraction accounts for topographic effects on irradiance (Adams et al., 1993). The estimates of subpixel vegetation cover, rock cover, and other surface cover are determined with Eq. (4) as well.

\subsection{MODSCAG model}

MODSCAG analyzes individual linear spectral mixtures for each permutation of two or more endmembers of the spectral library, in which no more than one endmember from a surface cover class is present (i.e., at most one snow endmember). A model is considered valid if: (a) spectral fractions are in the range [-0.01, 1.01], (b) overall RMSE $<2.5 \%$, and (c) no three spectrally consecutive residuals exceed $2.5 \%$. The use of consecutive residuals reinforces conformity of the modeled spectrum to the measured spectrum across the spectrum. In order to account for pixels with spectral reflectances not modeled under 
the above constraints (e.g. steep south facing slopes for which MOD09GA reports HDRF $>1.0$ ), a duplicate set of model runs are subject to looser constraints of (a) $[-1.01,2.01]$, (b) overall RMSE $<5 \%$, and (c) no three spectrally consecutive residuals exceed $5 \%$.

Two-endmember models (physical endmember plus photometric shade) determine which endmembers can be scaled to match the MODIS reflectance spectrum within the modeling constraints. Models with three or more endmembers encompass proper mixture analysis. For example, a potential three-endmember model would consist of a snow endmember of grain radius $250 \mu \mathrm{m}$, coniferous forest, and photometric shade. For each $N$-endmember suite of models that meet the constraints for a pixel, MODSCAG selects the snow area and grain size values associated with the smallest error and the tighter constraints. MODSCAG then attributes to the pixel the snow-covered area and snow grain size of the valid model that has the fewest endmembers, because the solution with more endmembers is mathematically trivial relative to that with fewer endmembers (that is, it is easier to model a vector with increasing basis vectors that are not degenerate). Fig. 2 shows a set of MODSCAG results for a winter day in the Sierra Nevada.



snow cover (lower left), and grain size (lower right). (For interpretation of the references to colour in this figure legend, the reader is referred to the web version of this article.) 
In the research mode of MODSCAG, each pixel of the MODIS scene is subjected to order 10,000 models with each pixel likely to have a different model combination varying according to snow grain size (snow endmember), vegetation or soil type, and the fractions of these. A complete run of research MODSCAG for the Sierra Nevada region ( 875 samples by 1450 lines, 7 bands, short integer) requires 90 min of CPU time on an AMD Athlon XP2800+CPU, 2 GHz clock speed and 1 GB of memory. The operational version that is in testing has improved logic and currently requires order $10^{3}$ fewer operations with a CPU expense of $\sim 0.9 \mathrm{~s}$. With the Earth's land surface area being 150 million $\mathrm{km}^{2}$, the projected upper bound of computational expense for mapping the globe at $500 \mathrm{~m}$ spatial footprint without optimization for regions with no snow cover or illumination is $6.7 \mathrm{~h}$. This version is undergoing testing as of writing of this paper.

The broadband albedo $\alpha$ of clean snow (Fig. 3 ) is determined from the selected subpixel grain size, $r$, through the following relationship that is fit to results from the radiative transfer modeling of snow endmembers and albedo:

$\alpha=1-A\left(\theta_{0}\right) r^{B\left(\theta_{0}\right)}$

The coefficient $A$ and exponent $B$ are sensitive to the illumination angle $\theta_{0}$ (Table 2). A subsequent version of the model will include a coupled spectral/textural approach to use dirty snow endmembers and more complete inversion for snow albedo. The difficulties lie in the need to use absolute reflectance values to estimate impurities, whereas grain size can be derived from relative spectral values. Retrieval of impurity content, along with vertical variability in grain size, from ADEOS-II GLI data has been demonstrated (Aoki et al., 2007; Hori et al., 2007), but only for flat or nearly flat surfaces where the solar illumination angle is known. In mountainous terrain, one needs to co-register the imagery with digital elevation data, and small errors in the elevation data translate into much larger errors in the calculation of slope and thereby in local solar illumination angle. A generalized MODIS-based retrieval of impurity content in the mountain snow cover remains an area where further research is needed.

MODSCAG incorporates the following assumptions: (a) the variability in the hemispherical-directional reflectance factor for the solar geometry and atmospheric conditions at the time of each MODIS acquisition is negligible, i.e., $R_{\lambda}\left(\theta_{0}, \phi_{0}, 0,0\right) \approx R_{\lambda}\left(\theta_{0}, \phi_{0}, \theta_{r}, \phi_{r}\right)$ within the range of angles $\left[\theta_{r}, \phi_{r}\right]$ observed from MODIS; (b) the effects of impurities and the effects of thin snow on snow spectral reflectance are not separable and these effects do not impact retrievals of snow

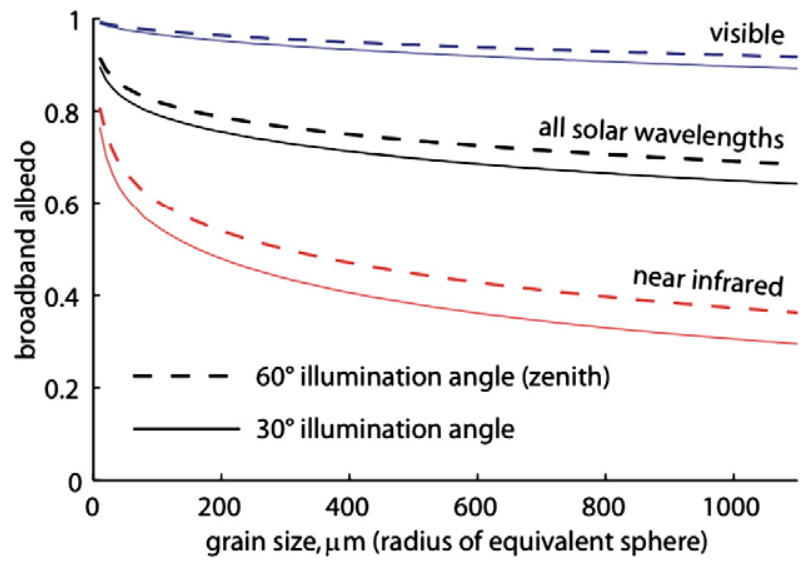

Fig. 3. Relationship between grain size (optically equivalent sphere) and broadband albedo for direct irradiance at $30^{\circ}$ and $60^{\circ}$ illumination angles (from zenith) for the visible and nearinfrared parts of the solar spectrum and the whole solar spectrum. Many Mie scattering and multiple scattering calculations are needed to generate the figure, but the curves can be fit with Eq. (5). Table 2 gives values for the A and B coefficients for illumination angles $30^{\circ}$ and $60^{\circ}$.
Table 2

Coefficients in the equations that fit the curves in Fig. 3, from Eq. (5)

\begin{tabular}{llllll}
\hline & \multicolumn{2}{l}{$30^{\circ}$ illumination angle } & & \multicolumn{2}{c}{$60^{\circ}$ illumination angle } \\
\cline { 2 - 3 } & $\mathrm{A}$ & & $\mathrm{A}$ & 0.0029 & $\mathrm{~B}$ \\
\hline Visible & 0.0040 & 0.4730 & & 0.4791 \\
All solar wavelengths & 0.0765 & 0.2205 & & 0.0648 & 0.2258 \\
Near-infrared & 0.2025 & 0.1791 & & 0.1689 & 0.1906 \\
\hline
\end{tabular}

area and grain size; (c) linear spectral mixture analysis is valid for multispectral scenes of alpine terrain; and (d) liquid water in the snow does not affect the retrievals of snow-covered area and grain size. The following paragraphs discuss these four assumptions:

(a) Painter and Dozier (2004) specifically investigated the assumption that we can ignore directional effects in the reflected radiation. In an analysis with imaging spectrometer data, they found that for all view azimuths other than the forward direction, errors in fractional snow cover were less than $5 \%$ and errors in albedo were less than $4 \%$. For the view into the forward reflectance direction, at large off-nadir viewing angles, anisotropic reflectance can cause errors in the estimate of fractional snow cover. However, at off-nadir viewing angles, the MODIS pixel increases in size also, thereby sampling a larger area than at nadir. The maximum MODIS scan angle is $\pm 55^{\circ}$ from nadir; thus the pixel dimensions at the edge of the scan are about twice as large in the along-track direction and nearly $5 \times$ as large crosstrack, so nearly $10 \times$ the area (Dozier et al., in press). This sampling issue causes a much bigger uncertainty in the estimation of snow properties than do directional effects in the reflectance. However, for changes in local view zenith due to topographic variation, the problem can be significant. This version of the model does not account for subpixel variability in topography.

(b) To thoroughly address the impurity component requires coupling topographic modeling using digital elevation data, such as those from the Shuttle Radar Topography Mission (Farr et al., 2007), with an empirical approach that is presently in development. Large areas of bare ground and optically thick snow undoubtedly accompany shallow snow that lies in a $500 \mathrm{~m}$ ground-instantaneous field-of-view. Therefore, we consider the separation of shallow snow from patchy snow to be intractable at $500 \mathrm{~m}$ spatial resolution.

(c) The validity of linear spectral mixture analysis in the snowmapping context has been validated in areas where trees are absent or sparse (Nolin \& Dozier, 1993; Painter et al., 1998; Rosenthal \& Dozier, 1996). With canopy-level spectra, the nonlinearities in mixing can be treated as linear mixtures up to canopy densities beyond which no direct beam irradiance reaches the snow beneath. In such cases, we cannot quantify fractional snow cover and instead must resort to detecting snow's presence or absence. We are exploring at what canopy densities this threshold occurs and have published early results elsewhere (Liu et al., 2008).

(d) Imaging spectrometer data can estimate values of liquid water in the surface layer (Green et al., 2006). However, the MODIS bands are too broad to detect the subtle shifts in the shape of the reflectance spectrum between wet and dry snow, hence retrievals with MODIS or another multispectral sensor are insensitive to liquid water in the snowpack.

\section{Validation}

We validate fractional snow cover retrieval from MODIS using fractional snow cover estimated at $30 \mathrm{~m}$ resolution from temporally and spatially coincident Landsat $7 \mathrm{ETM}+$ and Landsat $5 \mathrm{TM}$ data in several regions: the study region for the Cold Land Processes 
Table 3

Information about ETM+/TM scenes used as ground truth and results of the binary and fractional comparisons

\begin{tabular}{|c|c|c|c|c|c|c|c|c|c|c|}
\hline Region & Landsat no. and path/row & Date & $\theta_{0}$ & $\phi_{0}$ & MODIS pixels & TM pixels & Precision & Recall & Accuracy & RMSE \\
\hline \multirow[t]{11}{*}{ CLPX } & \multirow[t]{6}{*}{ L7: $34 / 32$} & $2 / 15 / 2002$ & 58 & 149 & 133916 & $5.78 \mathrm{E}+07$ & 1.000 & 0.998 & 0.998 & 0.06 \\
\hline & & $3 / 3 / 2002$ & 53 & 147 & 110637 & $4.82 \mathrm{E}+07$ & 1.000 & 1.000 & 1.000 & 0.11 \\
\hline & & $4 / 4 / 2002$ & 31 & 142 & 134721 & $5.79 \mathrm{E}+07$ & 1.000 & 1.000 & 1.000 & 0.05 \\
\hline & & $5 / 6 / 2002$ & 30 & 135 & 116994 & $5.47 \mathrm{E}+07$ & 1.000 & 0.997 & 0.999 & 0.04 \\
\hline & & $10 / 13 / 2002$ & 52 & 155 & 135011 & $5.81 \mathrm{E}+07$ & 1.000 & 1.000 & 1.000 & 0.02 \\
\hline & & $11 / 30 / 2002$ & 65 & 159 & 129373 & $5.51 \mathrm{E}+07$ & 1.000 & 1.000 & 1.000 & 0.13 \\
\hline & \multirow[t]{5}{*}{ L7: $35 / 32$} & $11 / 2 / 2001$ & 58 & 159 & 134018 & $5.70 \mathrm{E}+07$ & 1.000 & 1.000 & 1.000 & 0.02 \\
\hline & & $3 / 10 / 2002$ & 50 & 146 & 85933 & $4.35 \mathrm{E}+07$ & 1.000 & 1.000 & 1.000 & 0.10 \\
\hline & & $5 / 13 / 2002$ & 29 & 133 & 126666 & $5.56 \mathrm{E}+07$ & 0.937 & 1.000 & 0.989 & 0.03 \\
\hline & & $1 / 8 / 2003$ & 67 & 155 & 123182 & $5.30 \mathrm{E}+07$ & 1.000 & 1.000 & 1.000 & 0.08 \\
\hline & & $3 / 13 / 2003$ & 49 & 146 & 132711 & $5.75 \mathrm{E}+07$ & 1.000 & 1.000 & 1.000 & 0.07 \\
\hline \multirow[t]{5}{*}{ Rio Grande } & \multirow[t]{5}{*}{ L7: $34 / 34$} & $4 / 1 / 2001$ & 39 & 140 & 101316 & $4.87 \mathrm{E}+07$ & 0.999 & 0.999 & 0.999 & 0.07 \\
\hline & & $4 / 17 / 2001$ & 34 & 136 & 131659 & $5.69 \mathrm{E}+07$ & 1.000 & 1.000 & 1.000 & 0.05 \\
\hline & & $4 / 4 / 2002$ & 38 & 139 & 129072 & $5.61 \mathrm{E}+07$ & 1.000 & 1.000 & 1.000 & 0.04 \\
\hline & & $5 / 6 / 2002$ & 29 & 130 & 124514 & $5.58 \mathrm{E}+07$ & 0.999 & 1.000 & 1.000 & 0.02 \\
\hline & & $5 / 22 / 2002$ & 26 & 124 & 132831 & $5.74 \mathrm{E}+07$ & 1.000 & 0.993 & 1.000 & 0.02 \\
\hline \multirow[t]{12}{*}{ Sierra Nevada } & \multirow[t]{2}{*}{ L5: $41 / 35$} & $3 / 17 / 2004$ & 45 & 138 & 90896 & $3.94 \mathrm{E}+07$ & 1.000 & 1.000 & 1.000 & 0.04 \\
\hline & & $4 / 8 / 2006$ & 36 & 137 & 75777 & $3.19 \mathrm{E}+07$ & 0.998 & 1.000 & 0.999 & 0.06 \\
\hline & \multirow[t]{3}{*}{ L7: $42 / 34$} & $7 / 27 / 2000$ & 28 & 123 & 135273 & $5.81 \mathrm{E}+07$ & 1.000 & 1.000 & 1.000 & 0.01 \\
\hline & & $5 / 14 / 2002$ & 27 & 127 & 132023 & $5.69 \mathrm{E}+07$ & 1.000 & 0.995 & 0.998 & 0.05 \\
\hline & & $7 / 1 / 2002$ & 25 & 117 & 131907 & $5.67 \mathrm{E}+07$ & 0.996 & 0.996 & 1.000 & 0.01 \\
\hline & L5: $42 / 34$ & $3 / 8 / 2004$ & 50 & 141 & 134174 & $5.78 \mathrm{E}+07$ & 1.000 & 1.000 & 1.000 & 0.06 \\
\hline & \multirow[t]{4}{*}{ L7: 43/33 } & $3 / 12 / 2000$ & 48 & 145 & 95992 & $4.09 \mathrm{E}+07$ & 1.000 & 1.000 & 0.999 & 0.05 \\
\hline & & $7 / 18 / 2000$ & 27 & 124 & 132899 & $5.75 \mathrm{E}+07$ & 1.000 & 1.000 & 1.000 & 0.00 \\
\hline & & $2 / 27 / 2001$ & 53 & 147 & 134983 & $5.80 \mathrm{E}+07$ & 1.000 & 1.000 & 1.000 & 0.05 \\
\hline & & $4 / 3 / 2002$ & 40 & 141 & 122998 & $5.31 \mathrm{E}+07$ & 1.000 & 1.000 & 1.000 & 0.04 \\
\hline & \multirow[t]{2}{*}{ L5: $43 / 33$} & $3 / 15 / 2004$ & 48 & 141 & 133113 & $5.72 \mathrm{E}+07$ & 1.000 & 1.000 & 1.000 & 0.05 \\
\hline & & $4 / 6 / 2006$ & 38 & 141 & 104129 & $4.19 \mathrm{E}+07$ & 1.000 & 0.999 & 0.999 & 0.09 \\
\hline \multirow[t]{3}{*}{ Himal } & \multirow[t]{2}{*}{ L7: $140 / 41$} & $3 / 10 / 2002$ & 42 & 135 & 128805 & $5.62 \mathrm{E}+07$ & 1.000 & 1.000 & 1.000 & 0.07 \\
\hline & & $5 / 13 / 2002$ & 24 & 107 & 88057 & $4.01 \mathrm{E}+07$ & 0.999 & 1.000 & 0.999 & 0.09 \\
\hline & L7: $142 / 40$ & $4 / 3 / 2000$ & 33 & 130 & 119139 & $5.32 \mathrm{E}+07$ & 1.000 & 1.000 & 1.000 & 0.08 \\
\hline
\end{tabular}

All angles are in degrees, $\theta_{0}$ is the center solar zenith angle, and $\phi_{0}$ is the center solar azimuth angle.

Experiment in the Colorado Rocky Mountains, the Annapurna and Khumbu Himal regions of the Himalaya, the headwaters of the Upper Rio Grande, and the Sierra Nevada of California. TMSCAG, a new version of the Rosenthal and Dozier (1996) spectral mixing model adapted to the ETM+ bandpasses and radiometric characteristics, retrieves fractional snow cover from the ETM+ and TM data.

Our approach to validation uses Landsat TM pixels within a radius of $r \sqrt{2}$ from the center of a MODIS pixel, where $r$ ranges from $500 \mathrm{~m}$ to $2 \mathrm{~km}$, to assess MODSCAG error from native $500 \mathrm{~m}$ resolution at nadir to coarser resolution that accommodates MODIS geolocation uncertainties of 0.5 pixel RMS error (Wolfe et al., 2002).

Top-of-atmosphere reflectance is calculated using the 2003 lookup table for Landsat 5 (Chander \& Markham, 2003) and the standard equations from the Landsat 7 Science Data Users Handbook (Landsat Project Science Office, 2008). Surface reflectance is estimated using the 6S model (Kotchenova et al., 2006; Kotchenova \& Vermote, 2007), tailored to incorporate a digital elevation model to vary the atmospheric optical thickness.

Water masks for the conterminous United States were created from the National Land Cover Dataset (Homer et al., 2007). Water masks for the Himalaya images were created manually. To avoid masking snow-covered lakes, pixels are considered water and masked only if their reflectance is less than $10 \%$ in each visible, near-infrared, and shortwave infrared band.

\subsection{Validation regions for snow-covered area}

The Cold Land Processes Experiment was carried out in northcentral Colorado in winter and spring of 2002 and 2003. We validated MODSCAG retrievals within the Small-Regional Study Area $\left(39.5^{\circ}\right.$ to $41^{\circ} \mathrm{N}, 105^{\circ}$ to $107.5^{\circ} \mathrm{W}$ ). This region has a predominantly continental snow regime with some pockets of intermountain characteristics. Vegetation ranges from high elevation grasslands to coniferous and deciduous forests of varying density.
The Annapurna $\left(28.6^{\circ} \mathrm{N}, 83.8^{\circ} \mathrm{E}\right)$ and Khumbu Himal $\left(27.9^{\circ} \mathrm{N}\right.$, $86.9^{\circ} \mathrm{E}$ ) study regions span the border between Nepal and the Tibetan Autonomous Region in the Himalaya. Monsoonal variation drives the region's climate with significant snow accumulation in mid-winter from western flow and in late spring from southwesterly monsoonal flow. Elevations range from $1000 \mathrm{~m}$ to $8850 \mathrm{~m}$ with dense vegetation and no snowfall at the lowest elevations, grass and shrubs at middle elevations, and exposed rock and snow at elevations greater than about $5000 \mathrm{~m}$.

The snow-covered part of the Upper Rio Grande includes portions of the San Juan Mountains of southwest Colorado and the Sangre de Cristo Mountains of south central Colorado, which have a strong continental climatic regime. Elevations range from 2280 to over $4300 \mathrm{~m}$ with scene center of $36.9^{\circ} \mathrm{N}$ and $106.5^{\circ} \mathrm{W}$. Land cover ranges

Table 4

Binary and fractional performance metrics for comparing MODSCAG with Landsat fractional snow cover

\begin{tabular}{ll}
\hline Performance measure & Definition \\
\hline $\begin{array}{l}\text { Precision } \\
\text { Recall }\end{array}$ & $\frac{\mathrm{TP}}{\mathrm{TP}+\mathrm{FP}}$ \\
Accuracy & $\frac{\mathrm{TP}}{\mathrm{TP}+\mathrm{FN}}$ \\
& $\frac{\mathrm{TP}+\mathrm{TN}}{\mathrm{TP}+\mathrm{TN}+\mathrm{FP}+\mathrm{FN}}$ \\
RMSE & $\sqrt{\frac{1}{(N-1)} \sum_{j=1}^{N}\left[\mathrm{MODIS} f_{\mathrm{SCA}}(j)-\text { Landsat } f_{\mathrm{SCA}}(j)\right]^{2}}$ \\
& where $N=$ number of Landsat pixels with $f_{\mathrm{SCA}} \geq$ threshold
\end{tabular}

TP: true positive (snow in the MODIS and Landsat pixels at same resolution). $T N$ : true negative (no snow in either the MODIS or Landsat pixel).

FP: false positive (snow in the MODIS pixel but not in the Landsat pixel). FN: false negative (snow in the Landsat pixel but not in the MODIS pixel). $f_{\mathrm{SCA}}$ : fractional snow cover in the pixel, either MODIS or Landsat. 
Cold Land Processes Experiment Rocky Mountains

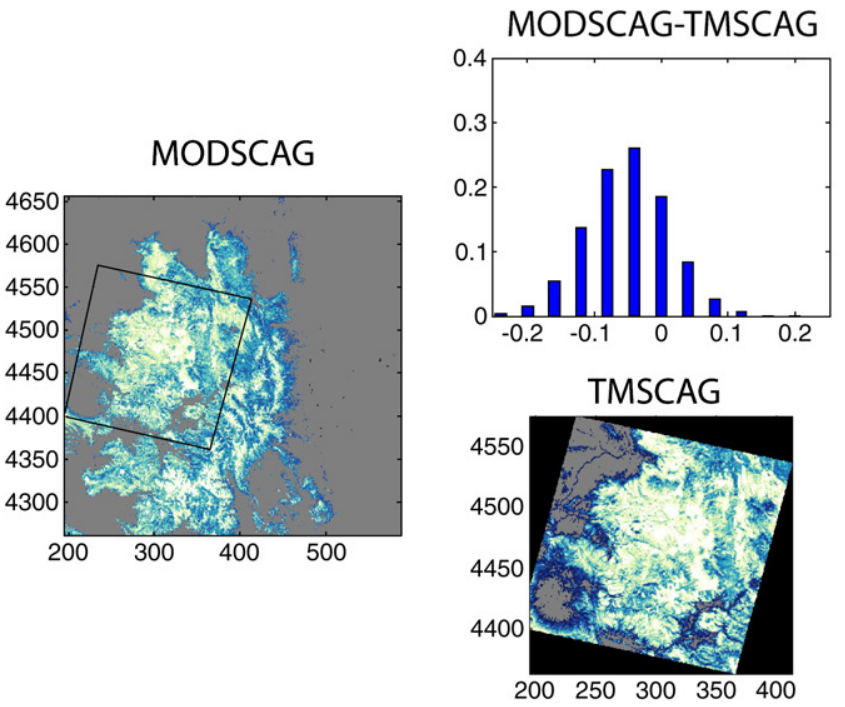

\section{Sierra Nevada}

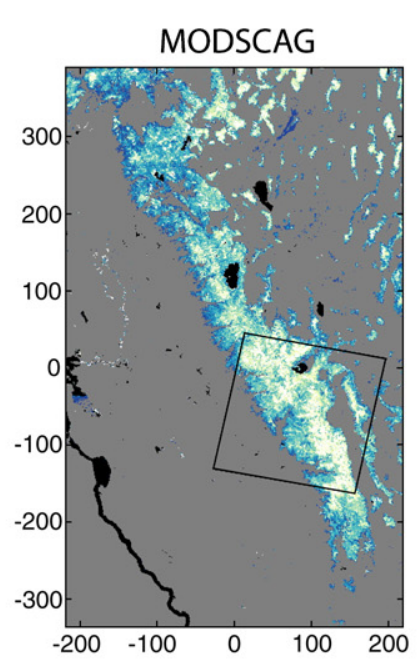

\section{Annapurna and Khumbu Himal}


\section{Upper Rio Grande}
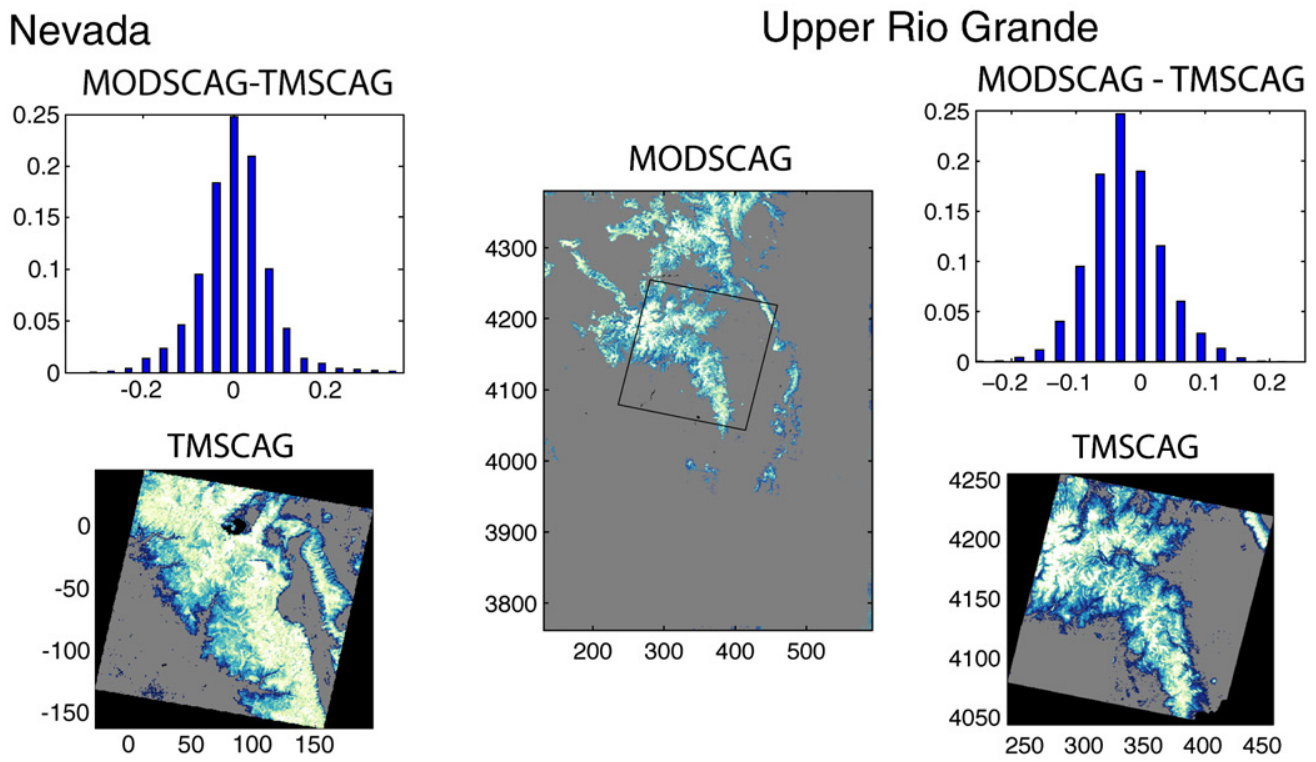

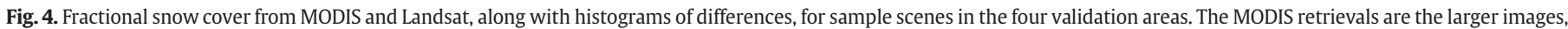
and they show the bounding boxes of the finer-resolution Landsat images. The black areas are masks, either because of water bodies or lack of data.

from agricultural fields of the San Luis Valley through coniferous and deciduous forests to alpine tundra and exposed rock and soil.

The Sierra Nevada of California has a predominantly maritime snow regime of deep snow with some high-elevation areas more similar to the drier snow of the intermountain regime. The mountain range trends from northwest to southeast bounded on the west by the San Joaquin Valley and on the east by the Great Basin (scene center of $38.3^{\circ} \mathrm{N}$ and $119.9^{\circ} \mathrm{W}$ ). Elevations range from the foothills that transition into the San Joaquin Valley at a few hundred meters elevation to Mt. Whitney at $4421 \mathrm{~m}$, the highest point in the conterminous U.S. Vegetation includes coniferous forests, mixed forests, alpine tundra, meadows, and brush.

Eight unique Landsat World Reference System (WRS2) path/row combinations span the four study areas. Table 3 shows the specific image dates (October-July) and accompanying scene characteristics as well as solar zenith angle for the corresponding MODIS images. Solar zenith angles for the images range from $27^{\circ}$ to $67^{\circ}$, while solar azimuth angles range from $107^{\circ}$ to $159^{\circ}$. Note that the view zenith angle is less than $8^{\circ}$ for most MODIS images in order to best assess the MODSCAG algorithm itself with the near-nadir TM and ETM+ data.

\subsection{Saturation Issues}

ETM+ and TM frequently saturate over snow in bands 1 through 3, resulting in a spectrum with artificially low apparent reflectance in the visible wavelengths. Landsat TM has a larger dynamic range in bands 2 and 3 than ETM+, resulting in fewer saturated pixels in bands 2 and 3. Raw spectral mixture analyses of these saturation-afflicted reflectance spectra result in erroneously low estimates of snow fraction. Therefore, when the three visible bands are saturated, we assume $100 \%$ snow cover. This assumption can represent an overestimate if subpixel rock or vegetation is present, but this is the most reasonable assumption with the given information. In the scenarios of bands 1 and 3 saturated or band 1 only saturated, we perform spectral mixture analysis on the remaining bands. 
CLPX, Difference Histograms at 2km
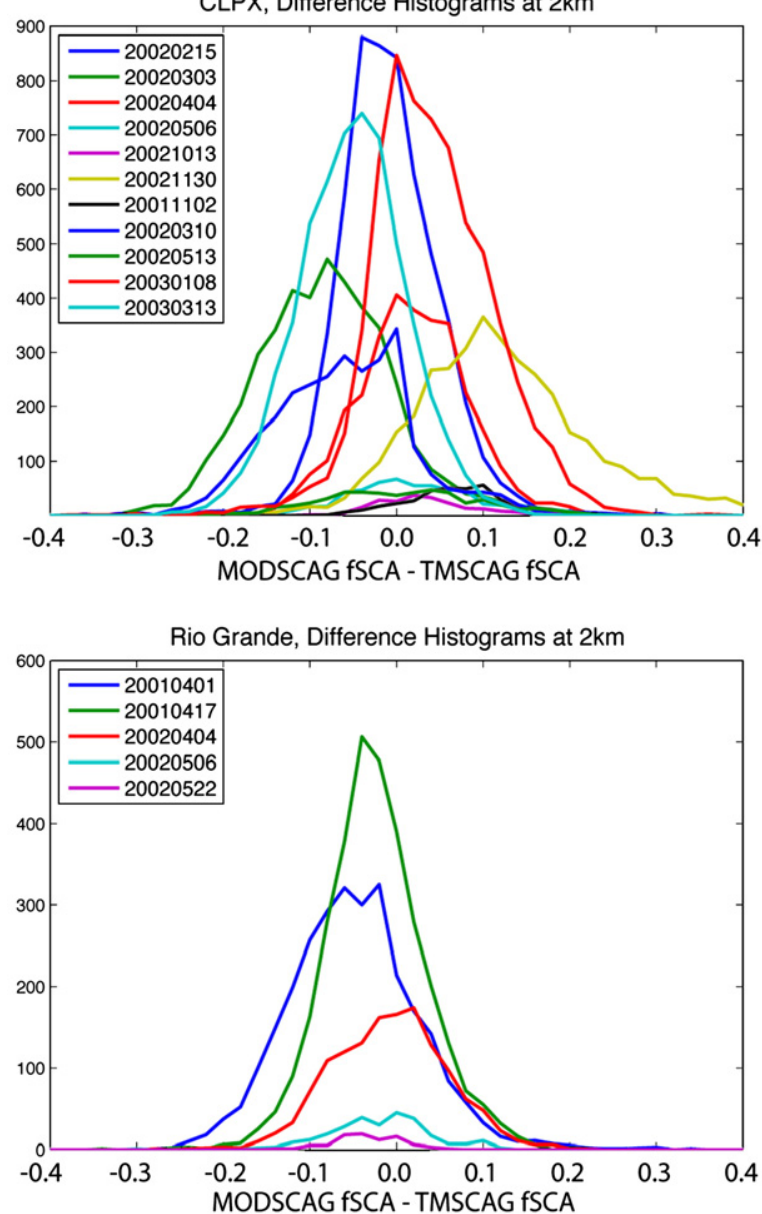

Himalaya, Difference Histograms at 2km



Sierra Nevada, Difference Histograms at $2 \mathrm{~km}$



Fig. 5. Histograms of all differences between MODIS and Landsat snow cover for the validation regions.

\subsection{Grain size and albedo}

The physical parameter that most affects snow reflectance is an effective grain radius defined by the specific surface area, i.e. the surfaceto-volume ratio (Dozier \& Warren, 1982; Warren, 1982). However, existing data sets with which to validate MODIS retrievals have been collected as grain size measured in the field, where often the effective grain radius is overestimated because the observers tend to focus on the larger grains (Painter et al., 2007b). Here, we validate grain size retrievals with measurements made during the Cold Land Processes Experiment (http://nsidc.org/data/clpx/). The field teams were trained to estimate representative grain sizes instead of the largest grains.

Validation of remotely sensed snow albedo uses temporally coincident measurements from the Senator Beck Basin in the San Juan Mountains. The Senator Beck Basin includes two energy balance towers at $3368 \mathrm{~m}$ and $3718 \mathrm{~m}$, where detailed radiation measurements are made. Elevations in the basin range from $2000 \mathrm{~m}$ to over $4000 \mathrm{~m}$, with much of the terrain above timberline. Snow albedo is measured in a study plot in the Senator Beck Basin with Kipp \& Zonen CM21 broadband pyranometers with spectral responses from 0.305 to $2.8 \mu \mathrm{m}$ wavelength. The albedo relationship for MODSCAG retrieved grain sizes comes from radiative transfer modeling of spectral albedo.

\section{Results}

\subsection{Fractional snow covered area}

We compare the performance of MODSCAG with Landsat using two sets of metrics. The first set is also suitable for binary (snow/no-snow) mapping: Do MODIS and Landsat find snow in the same places? Taking Landsat as "truth" for pixels that either have snow or do not (above a fractional snow cover threshold of $15 \%$ ), we compare those results with the pixels where MODSCAG identifies snow at the same threshold. Table 4 shows the normal metrics used to evaluate image classification performance-Precision, Recall, and Accuracy. The second set of metrics, also defined in Table 4, compares the fractional snow cover $\left(f_{\text {SCA }}\right)$ values from MODIS and Landsat, for those pixels where either MODIS or Landsat has identified snow (otherwise the vast majority of the pixels have zero $f_{\text {SCA }}$ identified by both sensors). We calculate the difference between MODIS $f_{\text {SCA }}$ and Landsat $f_{\text {SCA }}$ for each pixel and compute the RMS error for those values.

\subsection{Binary metrics}

Precision describes the percentage of all positive mapping results that truly identify snow. Across the 31 validation scenes, precision ranged from 93.7 to $100 \%$, with a mean precision across all scenes of $99.8 \%$. Recall describes the fraction of all snow in the scene that is identified. Across the validation scenes, all recalls were greater than $99.2 \%$ with an average of $99.9 \%$. Accuracy describes the percentage of all pixels that are correctly identified. All validation scenes have accuracies greater than $98.8 \%$, with an average of $99.9 \%$. Therefore, for the binary detection of snow cover, we can consider MODSCAG to perform at the 99.9\% level for all common metrics (Table 3 ). The precision metric shows that MODSCAG generally does not falsely identify snow cover, and the recall metric shows that MODSCAG generally detects all the snow that exists in the scene. The accuracy metric shows that MODSCAG generally classifies correctly pixels with and without snow. 




Fig. 6. Aggregated comparison of MODIS and Landsat fSCA results for all pixels with snow detected by either sensor in all scenes used in the validation.

\subsection{Fractional metrics}

In Fig. 4, we show fractional snow cover from MODIS and Landsat and the associated histogram of $f_{\mathrm{SCA}}(\mathrm{MODIS})-f_{\mathrm{SCA}}$ (Landsat) assessed at a $2 \mathrm{~km}$ spatial footprint, not the native $500 \mathrm{~m}$ resolution because that comparison introduces errors from the uncertainties in geolocation of MODIS and TM. For the subscenes shown, the RMS error is $6.3 \%$ for the CLPX, 4.2\% for the Sierra Nevada, 3.7\% for the Upper Rio Grande, and 7.6\% for the Himalaya. For all datasets listed in Table 3, RMS errors range from 1 to $13 \%$ with an average RMS error of $5 \%$, thus meeting a stated requirement of $10 \%$ accuracy for snow cover mapping (National Research Council, 1989). The larger RMS error for the Himalaya results from the consistent saturation of bands 1,2, and 3 of TM at these high elevations, thus causing a consistent (and biased) estimate of snow cover of 1.0 .

In Fig. 5, we show the region-by-region histograms of $f_{\mathrm{SCA}}$ differences. Generally, these errors are normally distributed with slight positive biases. The positive biases owe largely to the overprediction of $f_{\text {SCA }}$ in saturated pixels in Landsat images. In Fig. 6 , we show the scatter plot of MODSCAG versus TMSCAG for all scenes used in the validation. MODSCAG and TMSCAG match well except at the highest $f_{\text {SCA }}$ where saturation of TM results in perhaps erroneously high estimates. We can think of no plausible reasons that MODSCAG would underestimate $f_{\text {SCA }}$ at those levels while characterizing $f_{\mathrm{SCA}}$ well at all other fractions.

We expected that as solar zenith angle increases and magnitude of irradiance decreases, errors would increase. While the regressed relationship between RMS error and solar zenith angle is indeed positive (Fig. 7), these errors in $f_{\mathrm{SCA}}$ are relatively insensitive to the solar zenith angle with the relationship having $\mathrm{R}^{2}$ of 0.22 .

\subsection{Grain size validation}

We compared grain size retrievals in mixed pixels from MODSCAG with the surface grain size observations made in 2002 and 2003 during the Cold Land Processes Experiment (Fig. 8). These measurements came from regions with vegetation cover ranging from 0 to $80 \%$ ( $f_{\text {SCA }} 100 \%$ to $20 \%$ ). Each field value represents the mean of 16 surface measurements in each of the three, $1 \mathrm{~km}^{2}$ Intensive Study Areas for the Fraser and Rabbit Ears Meso-cell Study Areas (MSA).

The range of field grain sizes was 83 to $269 \mu \mathrm{m}$ with mean of $152 \mu \mathrm{m}$ whereas the range of MODSCAG-retrieved grain size was 90 to $300 \mu \mathrm{m}$ with a mean of $182 \mu \mathrm{m}$. The mean absolute error across the data was $51 \mu \mathrm{m}$ and the mean error was $30 \mu \mathrm{m}$, indicating that MODSCAG retrieves a larger grain size than that from the field measurements. Additionally, errors increased with increasing grain size. This result is consistent with the non-linear relationship between reflectance and grain size wherein a unit change in reflectance corresponds to a decreasing change in grain size as grain size increases. Results were similar between the two observation periods.

That MODSCAG retrieves greater grain sizes than the field measurements is unusual given that in general these algorithms tend to underpredict grain size at smaller sizes (Nolin and Dozier, 2000; Painter et al., 2003). However, the validation datasets in these previous works came largely from stereological analysis of preserved snow samples whereas the field measurements for CLPX were made by multiple observers with hand lenses and represent their best estimates of the minimum dimension of snow particles. As such, these measurements are not necessarily repeatable but do represent the best available data for the given regions. We suggest that in future campaigns such as CLPX that more quantitative and repeatable techniques be used to characterize snow optical grain size such as those that use local photography or spectroscopy (Matzl \& Schneebeli, 2006; Painter et al., 2007b).

The frequent saturation in the Landsat Thematic Mapper data hampers its utility to estimate grain size. When the visible bands are saturated, and the shortwave-infrared band is dark, we can assume the pixel is snow but with the saturated data we cannot calculate a grain size index (Dozier, 1984, 1989).

\subsection{Albedo validation}

In Fig. 9, we show the time series of snow albedo from MODSCAG and albedo at the Senator Beck study plot. Across the period, the mean error was $+3.6 \%$ whereas the mean absolute error was $4.2 \%$. Albedo from MODSCAG tracked the dynamics of the tower measurement of snow albedo but usually with positive bias. However, when the albedo at the tower was greater than $85 \%$, the bias generally disappeared and errors were reduced to $<1.5 \%$, suggesting that new snowfall before those measurements was relatively clean.

As noted, the albedo inferred with MODSCAG is for pure snow of the retrieved snow grain size. Impurities are generally found in midlatitude snow cover (Warren \& Wiscombe, 1980) and therefore, the estimate of albedo from MODSCAG will be positively biased and increasingly so as dust and soot concentrate at the snow surface in late spring (Painter et al., 2007a). The next version of MODSCAG will include treatment of impure snow endmembers to account for these

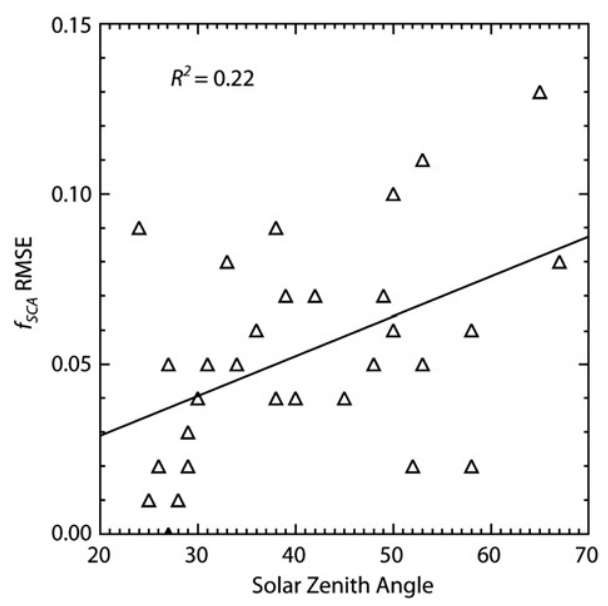

Fig. 7. Sensitivity of RMS error to solar zenith angle for 31 TM validation scenes. 




Fig. 8. Comparison of grain size retrievals in the Cold Land Processes Experiment for Rabbit Ears and Fraser Experimental Forest. Field-measured grain size is half the smallest observed dimension, considered to be the best measure by hand lens of the optical grain radius (Aoki et al., 2000).

substantial changes in albedo, and we will examine the effect of nonspherical particles, which produce more realistic angular distributions of snow reflectance (Kokhanovsky \& Zege, 2004).

The errors in this analysis are less than the order 7\% RMSE that Stroeve et al. (2005) found in comparison of snow albedo retrievals from MODIS (delivered in the MODIS version 4 products) with automatic weather stations on Greenland. In comparing the improved direct retrieval algorithm for MODIS data with in situ measurements of snow albedo in Greenland, Liang et al. (2005) found a residual standard error of $4 \%$ and an average bias of less than $2 \%$. The error of $4 \%$ is consistent with the magnitude of error from MODSCAG but the lower bias likely results from the generally cleaner snow in Greenland than in the midlatitude snow cover of the San Juan Mountains. Moreover, accounting for changes in directional reflectance is less complex on the Greenland ice sheet than in the mountains. While MODSCAG incorporates directional reflectances similarly to that used in the direct retrieval algorithm, it does not currently incorporate topographically modulated local directional geometry.

\section{Discussion}

The MODSCAG model solves simultaneously for fractional snow cover and grain size/albedo. As such, it gives a pixel-by-pixel estimate of fractional snow cover that accounts for changes in the snow and non-snow spectra and does not require the assumption of pure snow cover for the estimate of grain size/albedo.

Separate works have assessed the sensitivity of MODSCAG to changes in view zenith angle (Dozier et al., in press; Dozier \& Frew, in press; Liu et al., 2008). This sensitivity warrants separate treatment due to the intertwined complexities of spectral mixing, directional reflectance, and the instantaneous field-of-view near the edge of the scan. For example, Liu et al. (2008) show that $f_{S C A}$ retrievals by MODSCAG decrease over forest canopies with increasing view zenith angle, consistent with geometric optical modeling retrievals and hemispherical photographs acquired under the canopy. However, the pixel size at the edge of the MODIS scan is about $10 \times$ larger in area than a nadir pixel. When all pixels are down-sampled to the $250 \mathrm{~m}$ or $500 \mathrm{~m}$ resolution of the MODIS "land" bands, the off-nadir pixels include information from a much larger area than their nominal coordinates. The errors thereby introduced overwhelm other directional effects. Dozier et al. (in press) have therefore developed a space-time interpolation using the daily MODIS data to recover each day's best estimate of snow properties.

MODSCAG is a physically based and geographically consistent model. The current MODIS snow cover products available from the National Snow and Ice Data Center DAAC are empirical and therefore do not account for changes in snow physical properties. MODSCAG has the detection capacity down to $10 \%$ to $15 \% f_{\mathrm{SCA}}$, so it is able to detect snow cover at lower elevations near the snowline where much of the snow cover is in pixels where snow is not the largest surface cover. In some Sierra Nevada examples, this low-elevation snow cover that is completely missed by the binary algorithms amounts to $10-20 \%$ of the total snow (Dozier et al., in press). In the snow hydrology context, this snow will produce snowmelt runoff, and a runoff model cannot melt snow that the model's input data do not contain.

MODSCAG can also estimate the pixel-by-pixel uncertainty in $f_{\mathrm{SCA}}$ retrievals. Individual estimates of $f_{\mathrm{SCA}}$ by pixel inject unknown algorithm uncertainty and errors into hydrologic models that use $f_{\text {SCA }}$ results. However, data assimilation approaches (Clark et al., 2006) can incorporate the uncertainty information into ensemble approaches to understand uncertainty in hydrologic outputs.

MODSCAG is portable to other multispectral instruments that sample the visible through shortwave infrared spectrum. It has been selected as the Snow Cover product for the GOES-R Advanced Baseline Imager (ABI), scheduled for launch in the 2015 timeframe. While at

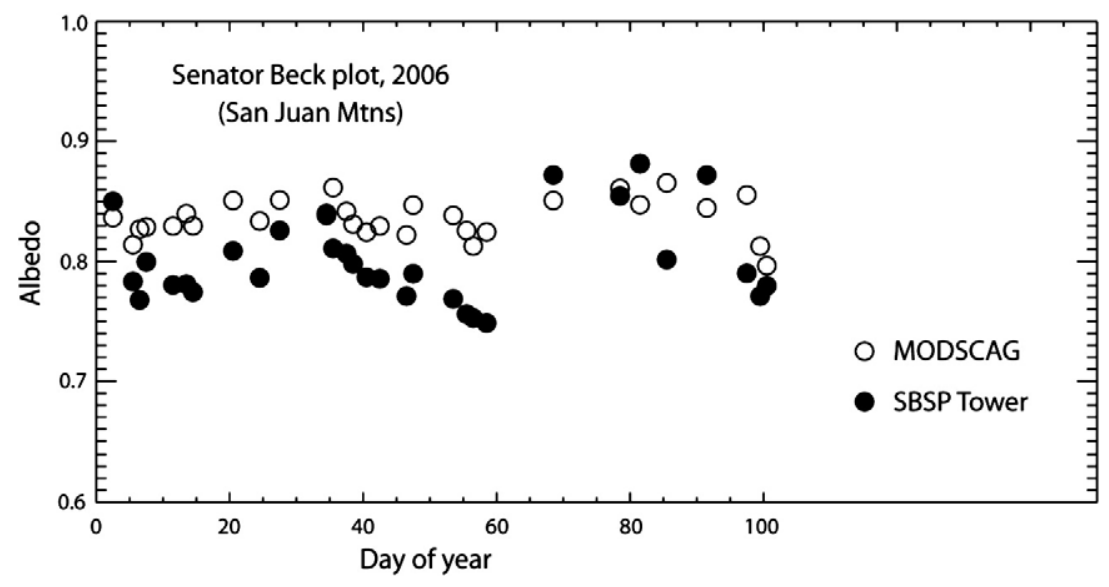

Fig. 9. Validation of MODSCAG albedo with field measurements of albedo made at the Senator Beck study plot, San Juan Mountains, Colorado in 2006. 
time of writing the snow cover algorithm for the NPOESS Preparatory Project (NPP) Visible Infrared Imaging Radiometer Suite (VIIRS) is a simple binary product, we strongly suggest that future NPOESS VIIRS should address snow cover requirements by using a model that derives fractional snow cover. The improvements in spectral sampling of these new imagers (GOES-R ABI, VIIRS) over previous operational instruments are intended to facilitate algorithmic and product advances that can meet the requirements of user bases of the civilian and military communities.

\section{Acknowledgements}

The work is supported by NASA Cooperative Agreement NNG04GC52A, Naval Postgraduate School Award N00244-07-1-0013, and NSF Grant ATM0432327. Anne Nolin and Preeti Tuladhar provided TM data for the Himalaya, as did Noah Molotch for the Upper Rio Grande. We acknowledge the efforts of the late Walter Rosenthal, who initiated the transfer of spectral mixing methods originally developed for imaging spectrometers into the domain of multispectral sensors.

\section{References}

Adams, J. B., Smith, M. O., \& Gillespie, A. R. (1993). Imaging spectroscopy: Interpretation based on spectral mixture analysis. In C. M. Pieters \& P. A. J. Englert (Eds.), Remote geochemical analysis: Elemental and mineralogical composition (pp. 145-166). New York: Cambridge University Press.

Aoki, T., Aoki, T., Fukabori, M., Hachikubo, A., Tachibana, Y., \& Nishio, F. (2000). Effects of snow physical parameters on spectral albedo and bidirectional reflectance of snow surface. Journal of Geophysical Research, 105(D8), 10219-10236.

Aoki, T., Hori, M., Motoyoshi, H., Tanikawa, T., Hachikubo, A., Sugiura, K., et al. (2007). ADEOS-II/GLI snow/ice products - Part II: Validation results using GLI and MODIS data. Remote Sensing of Environment, 111(2-3), 274-290. doi:10.1016/j.rse.2007.02.035

Asner, G. P., \& Heidebrecht, K. B. (2002). Spectral unmixing of vegetation, soil and dry carbon cover in arid regions: comparing multispectral and hyperspectral observations. International Journal of Remote Sensing, 23(19), 3939-3958. doi:10.1080/ 01431160110115960

Bales, R. C., Molotch, N. P., Painter, T. H., Dettinger, M. D., Rice, R., \& Dozier, J. (2006). Mountain hydrology of the western United States. Water Resources Research, 42, W08432. doi:10.1029/2005WR004387

Ballantine, J. A. C., Okin, G. S., Prentiss, D. E., \& Roberts, D. A. (2005). Mapping North African landforms using continental scale unmixing of MODIS imagery. Remote Sensing of Environment, 97(4), 470-483. doi:10.1016/j.rse.2005.04.023

Barnett, T. P., Adam, J. C., \& Lettenmaier, D. P. (2005). Potential impacts of a warming climate on water availability in snow-dominated regions. Nature, 438, 303-309. doi: $10.1038 /$ nature 04141

Barnett, T. P., Pierce, D. W., Hidalgo, H. G., Bonfils, C., Santer, B. D., Das, T., et al. (2008) Human-induced changes in the hydrology of the western United States. Science, 319(5866), 1080-1083. doi:10.1126/science.1152538

Blöschl, G. (1991). The influence of uncertainty in air temperature and albedo on snowmelt. Nordic Hydrology, 22, 95-108.

Chander, G., \& Markham, B. (2003). Revised Landsat-5 TM radiometric calibration procedures and postcalibration dynamic ranges. IEEE Transactions on Geoscience and Remote Sensing, 41(11), 2674-2677. doi:10.1109/TGRS.2003.818464

Clark, M. P., Slater, A. G., Barrett, A. P., Hay, L. E., McCabe, G. J., Rajagopalan, B., et al. (2006). Assimilation of snow covered area information into hydrologic and landsurface models. Advances in Water Resources, 29(8), 1209-1221. doi:10.1016/j. advwatres.2005.10.001

Crane, R. G., \& Anderson, M. R. (1984). Satellite discrimination of snow/cloud surfaces. International Journal of Remote Sensing, 5(1), 213-223. doi:10.1080/01431168408948799

Dennison, P. E., \& Roberts, D. A. (2003). Endmember selection for multiple endmember spectral mixture analysis using endmember average RMSE. Remote Sensing of Environment, 87(2-3), 123-135. doi:10.1016/S0034-4257(03)00135-4

Dozier, J. (1984). Snow reflectance from Landsat-4 Thematic Mapper. IEEE Transactions on Geoscience and Remote Sensing 22(3), 323-328, doi:10.1109/TGRS1984.350628

Dozier, J. (1989). Spectral signature of alpine snow cover from the Landsat Thematic Mapper. Remote Sensing of Environment, 28(1), 9-22. doi:10.1016/0034-4257(89)90101-6

Dozier, J., \& Frew, J. E. (2008), Computational provenance in hydrologic science: A snow mapping example. Philosophical Transactions of the Royal Society A, 367, 1021-1033.

Dozier, J., \& Painter, T. H. (2004). Multispectral and hyperspectral remote sensing of alpine snow properties. Annual Review of Earth and Planetary Sciences, 32, 465-494. doi:10.1146/annurev.earth.32.101802.120404

Dozier, J., Painter, T. H., Rittger, K., \& Frew, J. E. (2008), Time-space continuity of daily maps of fractional snow cover and albedo from MODIS, Advances in Water Resources, 31(1), 1515-1526.

Dozier, J., \& Warren, S. G. (1982). Effect of viewing angle on the infrared brightness temperature of snow. Water Resources Research, 18(5), 1424-1434.

Farr, T. G., Rosen, P. A., Caro, E., Crippen, R., Duren, R., Hensley, S., et al. (2007). The shuttle radar topography mission. Reviews of Geophysics, 45, RG2004. doi:10.1029/2005RG000183
Golub, G. H., \& Van Loan, C. F. (1996). Matrix computations, Johns Hopkins studies in the mathematical sciences (3rd ed.). Baltimore: Johns Hopkins University Press $694 \mathrm{pp}$.

Green, R. O., Painter, T. H., Roberts, D. A., \& Dozier, J. (2006). Measuring the expressed abundance of the three phases of water with an imaging spectrometer over melting snow. Water Resources Research, 42, W10402. doi:10.1029/2005WR004509

Hall, D. K., \& Riggs, G. A. (2007). Accuracy assessment of the MODIS snow products. Hydrological Processes, 21(12), 1534-1547. doi:10.1002/hyp.6715

Hall, D. K., Riggs, G. A., \& Salomonson, V. V. (2006). MODIS/Terra Snow cover daily L3 global $500 \mathrm{~m}$ grid V005, updated daily. National Snow and Ice Data Center.

Hall, D. K., Riggs, G. A., Salomonson, V. V., DiGiromamo, N., \& Bayr, K. J. (2002). MODIS snow-cover products. Remote Sensing of Environment, 83(1-2), 181-194. doi:10.1016/S0034-4257(02)00095-0

Homer, C., Dewitz, J., Fry, J., Coan, M., Hossain, N., Larson, C., et al. (2007). Completion of the 2001 National Land Cover Database for the conterminous United States. Photogrammetric Engineering and Remote Sensing, 73(4), 337-341.

Hori, M., Aoki, T., Stamnes, K., \& Li, W. (2007). ADEOS-II/GLI snow/ice products - Part III: Retrieved results. Remote Sensing of Environment, 111(2-3), 291-336. doi:10.1016/j. rse.2007.01.025

Howat, I. M., \& Tulaczyk, S. (2005). Climate sensitivity of spring snowpack in the Sierra Nevada. Journal of Geophysical Research, 110, F04021. doi:10.1029/2005JF000356

Kaufman, Y. J., Kleidman, R. G., Hall, D. K., Martins, J. V., \& Barton, J. S. (2002). Remote sensing of subpixel snow cover using 0.66 and $2.1 \mu \mathrm{m}$ channels. Geophysical Research Letters, 29(16), 1781. doi:10.1029/2001GL013580

Klein, A., \& Stroeve, J. (2002). Development and validation of a snow albedo algorithm for the MODIS instrument. Annals of Glaciology, 34, 45-52.

Kokhanovsky, A. A., \& Zege, E. P. (2004). Scattering optics of snow. Applied Optics, 43(7), 1589-1602. doi:10.1364/AO.43.001589

Kotchenova, S. Y., \& Vermote, E. F. (2007). Validation of a vector version of the 6S radiative transfer code for atmospheric correction of satellite data, Part II: Homogeneous Lambertian and anisotropic surfaces. Applied Optics, 46(20), 4455-4464. doi:10.1364/A0.46.004455

Kotchenova, S. Y., Vermote, E. F., Matarrese, R., \& Klemm, F. J., Jr. (2006). Validation of a vector version of the $6 \mathrm{~S}$ radiative transfer code for atmospheric correction of satellite data, Part I: Path radiance. Applied Optics, 45(26), 6762-6774. doi:10.1364/AO.45.006762

Landsat Project Science Office (2008). Landsat-7 Science Data User's Handbook. http:// landsathandbook.gsfc.nasa.gov/handbook.html

Liang, S., Stroeve, J., \& Box, J. E. (2005). Mapping daily snow/ice shortwave broadband albedo from Moderate Resolution Imaging Spectroradiometer (MODIS): The improved direct retrieval algorithm and validation with Greenland in situ measurement. Journal of Geophysical Research, 110, D10109. doi:10.1029/2004JD005493

Liu, J., Woodcock, C. E., Melloh, R. A., Davis, R. E., McKenzie, C., \& Painter, T. H. (2008) Modeling the view angle dependence of gap fractions in forest canopies: Implications for mapping fractional snow cover using optical remote sensing. Journal of Hydrometeorology, 9(5), 1005-1019. doi:10.1175/2008JHM866.1

Matzl, M., \& Schneebeli, M. (2006). Measuring specific surface area of snow by nearinfrared photography. Journal of Glaciology, 52(179), 558-564. doi:10.3189/ 172756506781828412

Mie, G. (1908). Beiträge zur Optik trüber Medien. Speziell Kolloidaler Metallösungen, Annalen der Physik, 25, 377-445.

Milly, P. C. D., Betancourt, J., Falkenmark, M., Hirsch, R. M., Kundzewicz, Z. W., Lettenmaier, D. P., et al. (2008). Stationarity is dead: whither water management? Science, 319(5863), 573-574. doi:10.1126/science.1151915

Mote, P. W., Hamlet, A. F., Clark, M. P., \& Lettenmaier, D. P. (2005). Declining mountain snowpack in western North America. Bulletin of the American Meteorological Society 86(1), 39-49. doi:10.1175/BAMS-86-1-39

National Research Council (1989). Prospects and concerns for satellite remote sensing of snow and ice. Washington, DC: National Academies Press 55 pp.

Neff, J. C., Ballantyne, A. P., Farmer, G. L., Mahowald, N. M., Conroy, J. L., Landry, C. C., et al. (2008). Increasing eolian dust deposition in the western United States linked to human activity. Nature Geosciences, 1, 189-195. doi:10.1038/ngeo133

Nolin, A. W., \& Dozier, J. (1993). Estimating snow grain size using AVIRIS data. Remote Sensing of Environment, 44, 231-238. doi:10.1016/0034-4257(93)90018-S

Nolin, A. W., \& Dozier, J. (2000). A hyperspectral method for remotely sensing the grain size of snow. Remote Sensing of Environment, 74(2), 207-216.

Nolin, A. W., Dozier, J., \& Mertes, L. A. K. (1993). Mapping alpine snow using a spectral mixture modeling technique. Annals of Glaciology, 17, 121-124.

Nussenzveig, H. M., \& Wiscombe, W. J. (1980). Efficiency factors in Mie scattering Physical Review Letters, 45(18), 1490-1494.

Okin, G. S. (2007). Relative spectral mixture analysis-A multitemporal index of total vegetation cover. Remote Sensing of Environment, 106(4), 467-479. doi:10.1016/j.rse.2006.09.018

Painter, T. H., Barrett, A. P., Landry, C., Neff, J., Cassidy, M. P., Lawrence, C., et al. (2007) Impact of disturbed desert soils on duration of mountain snowcover. Geophysical Research Letters, 34, L12502. doi:10.1029/2007GL030284

Painter, T. H., \& Dozier, J. (2004). Measurements of the hemispherical-directional reflectance of snow at fine spectral and angular resolution. Journal of Geophysical Research-Atmospheres, 109(D18), D18115. doi:10.1029/2003JD004458

Painter, T. H., Dozier, J., Roberts, D. A., Davis, R. E., \& Green, R. O. (2003). Retrieval of subpixel snow-covered area and grain size from imaging spectrometer data. $R e-$ mote Sensing of Environment, 85(1), 64-77. doi:10.1016/S0034-4257(02)00187-6

Painter, T. H., Molotch, N. P., Cassidy, M., Flanner, M., \& Steffen, K. (2007). Contact spectroscopy for determination of stratigraphy of snow optical grain size. Journal of Glaciology, 53(180), 121-127. doi:10.3189/172756507781833947

Painter, T. H., Roberts, D. A., Green, R. O., \& Dozier, J. (1998). The effect of grain size on spectral mixture analysis of snow-covered area from AVIRIS data. Remote Sensing of Environment, 65(3), 320-332. doi:10.1016/S0034-4257(98)00041-8 
Powell, R. L., Roberts, D. A., Dennison, P. E., \& Hess, L. L. (2007). Sub-pixel mapping of urban land cover using multiple endmember spectral mixture analysis: Manaus, Brazil. Remote Sensing of Environment, 106(2), 253-267. doi:10.1016/j.rse.2006.09.005

Roberts, D. A., Gardner, M., Church, R., Ustin, S. L., Scheer, G., \& Green, R. O. (1998). Mapping chaparral in the Santa Monica Mountains using multiple endmember spectral mixture models. Remote Sensing of Environment, 65(3), 267-279. doi:10.1016/S0034-4257(98) 00037-6

Roberts, D. A., Smith, M. O., \& Adams, J. B. (1993). Green vegetation, nonphotosynthetic vegetation, and soils in AVIRIS data. Remote Sensing of Environment, 44(2-3), 255-269.

Romanov, P., Tarpley, D., Gutman, G., \& Carroll, T. (2003). Mapping and monitoring of the snow cover fraction over North America. Journal of Geophysical Research, 108(D16) 8619. doi:10.1029/2002JD003142

Rosenthal, W., \& Dozier, J. (1996). Automated mapping of montane snow cover at subpixel resolution from the Landsat Thematic Mapper. Water Resources Research, 32(1), 115-130. doi:10.1029/95WR02718

Salomonson, V. V., \& Appel, I. (2004). Estimating fractional snow cover from MODIS using the normalized difference snow index. Remote Sensing of Environment, 89(3), 351-360. doi:10.1016/j.rse.2003.10.016

Salomonson, V. V., \& Appel, I. (2006). Development of the Aqua MODIS NDSI fractional snow cover algorithm and validation results. IEEE Transactions on Geoscience and Remote Sensing, 44(7), 1747-1756, doi:10.1109/TGRS.2006.876029

Scambos, T., Haran, T., Fahnestock, M., Painter, T. H., \& Bohlander, J. (2007). MODIS-based mosaic of Antarctica (MOA) data sets: Continent-wide surface morphology and snow grain size. Remote Sensing of Environment, 111(2-3), 242-257. doi:10.1016/j. rse.2006.12.020

Schaepman-Strub, G., Schaepman, M. E., Painter, T. H., Dangel, S., \& Martonchik, J. V. (2006). Reflectance quantities in optical remote sensing-Definitions and case studies. Remote Sensing of Environment, 103(1), 27-42. doi:10.1016/j.rse.2006.03.002
Stamnes, K., Li, W., Eide, H. Aoki, T., Hori, M., \& Storvold, R. (2007). ADEOS-II/GLI snow/ice products - Part I: Scientific basis. Remote Sensing of Environment, 111(2-3), 258-273. doi:10.1016/j.rse.2007.03.023

Stamnes, K., Tsay, S. C., Wiscombe, W. J., \& Jayaweera, K. (1988). Numerically stable algorithm for discrete-ordinate-method radiative transfer in multiple scattering and emitting layered media. Applied Optics, 27, 2502-2509.

Stroeve, J., Box, J. E., Gao, F., Liang, S., Nolin, A., \& Schaaf, C. (2005). Accuracy assessment of the MODIS 16-day albedo product for snow: Comparisons with Greenland in situ measurements. Remote Sensing of Environment, 94(1), 46-60. doi:10.1016/j. rse.2004.09.001

Tedesco, M., \& Kokhanovsky, A. A. (2007). The semi-analytical snow retrieval algorithm and its application to MODIS data. Remote Sensing of Environment, 111(2-3), 228-241. doi:10.1016/j.rse.2007.02.036

Vermote, E. F., \& Kotchenova, S. (2008). Atmospheric correction for the monitoring of land surfaces. Journal of Geophysical Research, 113, D23S90. doi:10.1029/ 2007JD009662

Vikhamar, D., \& Solberg, R. (2003). Snow-cover mapping in forests by constrained linear spectral unmixing of MODIS data. Remote Sensing of Environment, 88(3), 309-323. doi:10.1016/j.rse.2003.06.004

Warren, S. G. (1982). Optical properties of snow. Reviews of Geophysics and Space Physics, 20(1), 67-89.

Warren, S. G., \& Wiscombe, W. J. (1980). A model for the spectral albedo of snow, II, Snow containing atmospheric aerosols. Journal of the Atmospheric Sciences, 37(12), 2734-2745.

Wiscombe, W. J. (1980). Improved Mie scattering algorithms. Applied Optics, 19(9), 1505-1509.

Wolfe, R. E., Nishihama, M., Fleig, A. J., \& Kuyper, J. (2002). Achieving sub-pixel geolocation accuracy in support of MODIS land science. Remote Sensing of Environment, 83(1-2), 31-49. doi:10.1016/S0034-4257(02)00085-8 